\title{
Formation damage mechanism of a sandstone reservoir based on micro-computed tomography
}

\author{
Zhiyu Wang ${ }^{1,2}$, Hongxi $\mathrm{Li}^{3}$, Xuemei $\mathrm{Lan}^{4}$, Ke Wang ${ }^{1,2}$, Yongfei Yang ${ }^{1,2 \oplus *}$, Vadim Lisitsa ${ }^{5}$ \\ ${ }^{1}$ Key Laboratory of Unconventional Oil \& Gas Development (China University of Petroleum (East China)), Ministry of Education, \\ Qingdao 266580, P. R. China \\ ${ }^{2}$ Research Center of Multiphase Flow in Porous Media, School of Petroleum Engineering, China University of Petroleum (East China), \\ Qingdao 266580, P. R. China \\ ${ }^{3}$ Geological Exploration \& Development Research Institute, CNPC Chuanqing Drilling Engineering Company Limited, Chengdu 610051, \\ P. R. China \\ ${ }^{4}$ Exploration and Development Research Institute of PetroChina Southwest Oil \& Gas Field Company, Chengdu 610041, P. R. China \\ ${ }^{5}$ Institute of Petroleum Geology and Geophysics SB RAS, Novosibirsk 630090, Russia
}

Keywords:

Formation damage

pore structure variation

particle migration

microscopic seepage

Cited as:

Wang, Z., Li, H., Lan, X., Wang, K., Yang, Y., Lisitsa, V. Formation damage mechanism of a sandstone reservoir based on micro-computed tomography.

Advances in Geo-Energy Research, 2021, 5(1): 25-38, doi:

10.46690/ager.2021.01.04

\begin{abstract}
:
Formation damage caused by well drilling, completion, oil testing, oil recovery, and stimulation seriously affects oil and gas production, the evaluation of which plays an important role in the process of oilfield development. Thus, it is necessary to study formation damage mechanism from micro scale. In this study, two sets of displacement experiments were conducted using two sandstone samples and two chemical reagents. Each set was divided into three processes: first formation water injection, reverse chemical reagents injection and second formation water injection. According to the results of displacement experiments, the permeability changes of two sandstone samples were analyzed and the formation damage rates of different experimental processes were calculated respectively. In addition, we analyzed the formation damage of the two samples from the macroscopic aspect according to the changes of inlet pressure curves. We compared the pore structure changes of sandstone samples at different experiment processes by computed tomography (CT) images, and found the particle migration phenomenon. Based on the core sensitive regions observed by CT images, the pore network models of the sensitive regions were extracted to quantitatively characterize the change of pore structure parameters (pore radius, throat radius, coordination number and tortuosity). Finally, we designed a two-dimensional microscopic seepage channel model according to the real core structure. The flow rule of solid particles in fluid was simulated by finite element method, and the reason of reservoir clogging was analyzed. Through this study, we found that the injection of chemical reagents increased the inlet pressure and led to the decrease of core permeabilities. There was a negative correlation between the export rate of particle migration and matrix deformation degree.
\end{abstract}

\section{Introduction}

The formation damage during the process of oil \& gas production and well operation has the characteristics of long time, large area and high complexity. In some cases, different damage mechanisms could result in similar damage characteristics. During oilfield development, the formation damage leads to a decrease in permeability (Bagci et al., 2000; Moghadasi et al., 2004) and changes in wettability (Ali et al., 2019), which affect fluid injection capacity and well recovery.
The essential reason for formation damage is that the injected workover fluid is incompatible with the reservoir rock and formation liquid. Particle migration and clay expansion are the main reasons for blocking the seepage channels (Hussain et al., 2013; Luquot et al., 2014; Oliveira et al., 2014; Borazjani et al., 2017). In order to avoid or reduce the formation damage in field operation, it is of great significance to study the damage mechanism (Li et al., 2003; Wang et al., 2009; Lemon et al., 2011).

\footnotetext{
Yandy
Scientific

Press

${ }^{*}$ Corresponding author.

E-mail address: z18020047@s.upc.edu.cn (Z.Wang); lihx_dyy@cnpc.com.cn (H. Li); lanxuemei@petrochina.com.cn (X. Lan); s18020136@s.upc.edu.cn (K. Wang); yangyongfei@upc.edu.cn (Y. Yang); lisitsavv@ipgg.sbras.ru (V. Lisitsa). 2207-9963 (c) The Author(s) 2021.

Received December 12, 2020; revised December 28, 2020; accepted December 28, 2020; available online January 2, 2021.
} 
Table 1. Basic information of core samples.

\begin{tabular}{llll}
\hline Sample & Permeability $(\mathrm{mD})$ & Porosity $(\%)$ & Test \\
\hline $1 \#$ & 18.35 & 8.45 & Formation water and chemical reagent flooding and CT scanning \\
$2 \#$ & 13.54 & 8.12 & Formation water and chemical reagent flooding and CT scanning \\
\hline
\end{tabular}

Table 2. Mineral composition of the samples.

\begin{tabular}{llllll}
\hline Sample & Quartz (wt\%) & Potassium feldspar (wt\%) & Plagioclase (wt\%) & Calcite (wt\%) & Clay mineral (wt\%) \\
\hline $1 \#$ & 63 & 14 & 20 & 1 & 2 \\
$2 \#$ & 57 & 16 & 24 & 1 & 2 \\
\hline
\end{tabular}

In oil and gas field development, it is very difficult to study formation damage in the field, so laboratory study of formation damage is the best choice ( $\mathrm{Li}$ et al., 2016; Ma et al., 2016; Xu et al., 2016; Wang et al., 2020). We drilled some cores from a reservoir, and then tested them in the laboratory to obtain the experimental data. Finally, a comprehensive formation damage evaluation was carried out for the target reservoir. As an emerging method in the past decades, digital rock technology breaks some limitations of conventional experiments and has received more attentions in the oilfield development (Al-Yaseri et al., 2015; Klise et al., 2016; Liu et al., 2017; Wang et al., 2019). Through pore structure characterization and flow simulation, digital rock technology was used to study the percolation mechanism of reservoir fluids (Wang et al., 2012). By imaging and analyzing the dynamic change of pore structure during the displacement process, the formation damage of a sandstone reservoir was quantitatively evaluated, and fines migration were visualized (Yang et al., 2019).

In this study, we conducted two sets of displacement experiments, each of which was divided into three processes: first formation water injection, reverse reagent injection and second formation water injection. We evaluated the damage from the macroscopic aspect through the change of inlet pressure of core samples during the flooding experiment. Through the quantitative analysis of computed tomography (CT) images, the evidence of particle migration was found. The sensitive regions of core damage were observed through the extracted pore network models. Then, critical geometrical and topological properties of pore space were analyzed statistically. Finally, in order to explain the damage mechanism in more detail, we performed flow simulation and obtained the flow rules of particle migration under different pressures and degrees of matrix deformation.

\section{Methodology}

\subsection{CT scanning principle and equipment}

In recent years, due to the nature of non-destructive threedimensional imaging, the X-ray CT scanning technique has been widely used in the field of oil industry, including the measurement of improved oil recovery in carbonate reservoirs (Izgec et al., 2008; Luo et al., 2019), the microstructure analy-

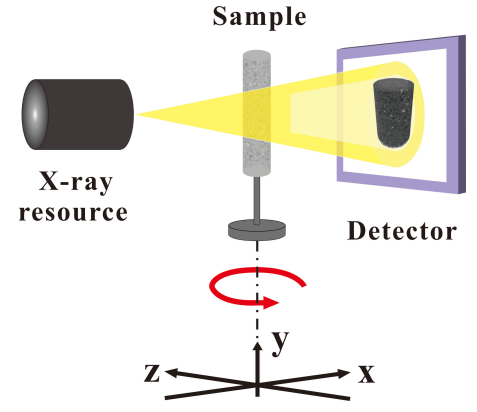

Fig. 1. Working principle of CT.

sis of shale rock with nanoscale pores (Guo et al., 2015; Zhang et al., 2017), and the identification of the occurrence pattern of gas hydrate deposits (Zhao et al., 2016; Ma et al., 2019).

The working principle of CT is shown in Fig. 1, where the $\mathrm{X}$-ray resource emits radiation to pass through the rotating sample. Then, the signal after decaying is received by the detector and processed finally.

Due to the different absorption degree of X-ray of the material elements at different locations, the attenuation coefficient of the X-ray after penetrating the material is also different. Eq. (1) is the attenuation coefficient formula of the X-ray.

$$
I=I_{o} e^{-\sum_{i} u_{i} x_{i}}
$$

where $I_{o}$ is the initial intensity of the X-ray, $I$ is the intensity of the X-ray after it passes through the object, $i$ is a component of the material in the path through which the X-ray passes, $u_{i}$ and $x_{i}$ are the attenuation coefficient of the $i$ component to $\mathrm{X}$-ray and the length of the component in the current path of $\mathrm{X}$-ray, respectively.

\subsection{Displacement experiment for formation damage}

To study the formation damage caused by chemical reagents, two groups of experiments were carried out with two core samples and two types of chemical reagents. Basic physical parameters and mineral composition of the experimental samples are shown in Tables 1 and 2, respectively. The fluids used in this experiment are formation water, chemical reagents from oil field operations. And the fluid composition 


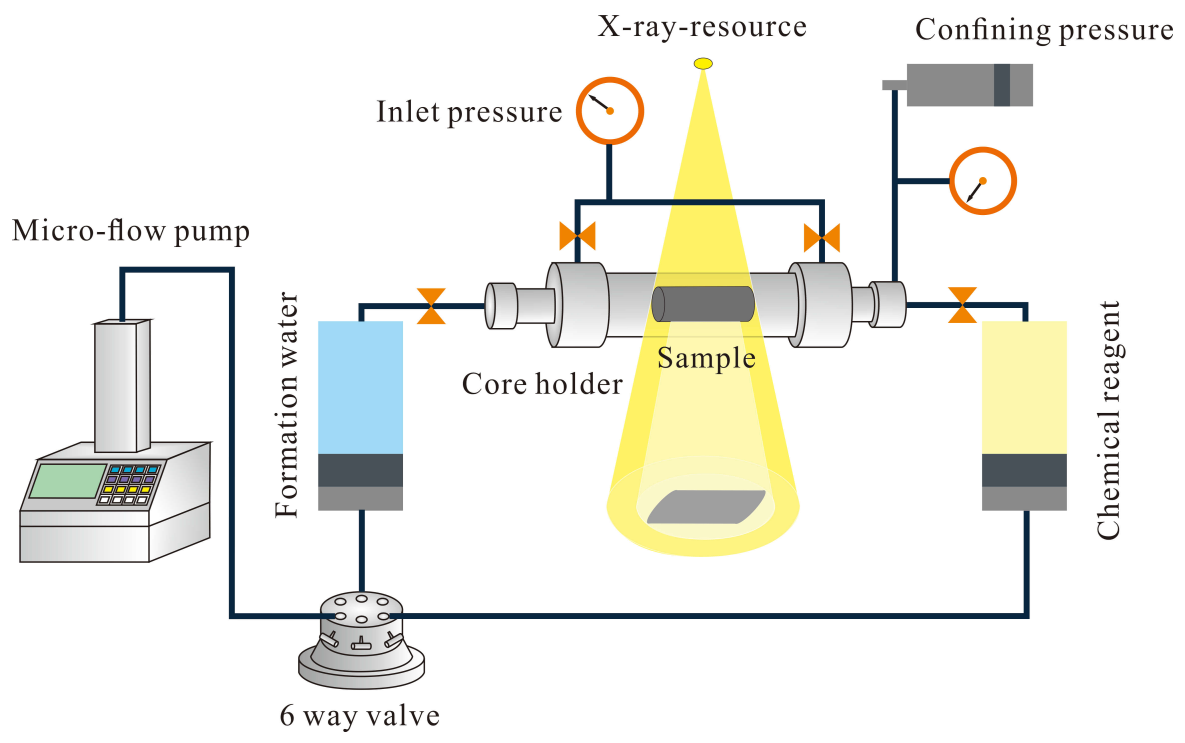

Fig. 2. Displacement experimental device.

Table 3. Ionic composition of fluids.

\begin{tabular}{|c|c|c|c|c|c|c|c|c|c|}
\hline \multirow{2}{*}{ Fluid } & \multicolumn{7}{|c|}{ Ion content $(\mathrm{mg} / \mathrm{L})$} & \multirow{2}{*}{ Salinity $(\mathrm{mg} / \mathrm{L})$} & \multirow{2}{*}{$\mathrm{pH}$} \\
\hline & $\mathrm{Cl}^{-}$ & $\mathrm{HCO}_{3}^{-}$ & $\mathrm{CO}_{3}^{2-}$ & $\mathrm{Ca}^{2+}$ & $\mathrm{Mg}^{2+}$ & $\mathrm{SO}_{4}^{2-}$ & $\mathrm{Na}^{+}$ & & \\
\hline Formation water & 324 & 3125 & 1061 & 2 & 44 & 303 & 2840 & 7742 & 8.2 \\
\hline Chemical reagent 1 & 1128 & 580 & 145 & 10 & 8 & 235 & 2815 & 4895 & 6.3 \\
\hline Chemical reagent 2 & 1342 & 265 & 115 & 16 & 6 & 285 & 1835 & 4853 & 5.9 \\
\hline
\end{tabular}

is presented in Table 3 .

The experimental device demonstrates two processes of formation water injection and reverse reagent injection, and the inlet pressure is equal to the differential pressure because of the zero outlet pressure, as shown in Fig. 2.

The selected sandstone rock samples were imaged before and after the displacement experiment using the MicroXCT400 machine (produced by Zeiss) at a resolution of $24 \mu \mathrm{m}$. Core holder was fixed on the sample stage and a $0.4 \times$ lens was used. CT images were acquired with an X-ray accelerating voltage of $110 \mathrm{kV}$. And exposure time was $2 \mathrm{~s}$, and each scan took $2 \mathrm{~h}$.

The detailed experimental procedure is as follows:

(1) First formation water injection: The core sample was placed in a core holder at formation temperature and the formation water was injected until it was fully saturated.

(2) CT scanning was performed on the core after first formation water injection, and obtained images were analyzed and processed.

(3) Reverse reagent injection: The chemical reagent was injected in the reverse direction at formation temperature. Inlet pressure and outlet velocity of the fluid were recorded until the inlet pressure was balanced.

(4) CT scanning was performed on the cores after reverse reagent injection, and obtained images were processed and analyzed.

(5) Second formation water injection: The formation water was injected again in the positive direction at forma- tion temperature. Inlet pressure and outlet velocity were recorded until the inlet pressure was balanced.

(6) CT scanning was performed on the core after second formation water injection, and obtained images were analyzed and processed.

(7) The damage rate was used to evaluate the formation damage due to chemical reagent injection quantitatively, which was defined as:

$$
D=\frac{K_{a}-K_{b}}{K_{a}} \times 100 \%
$$

where $K_{a}$ is the core permeability before chemical reagent injection, $K_{b}$ is the core permeability after the injection.

\subsection{Particle migration simulation}

In order to understand the mechanisms of particle migration more clearly, we designed a two-dimensional (2D) microscopic seepage channel model according to the real core structure. Compared with the three-dimensional (3D) model, 2D model could more intuitively reflect the behavior of grain migration in the porous media. In this study, the numerical simulation of the pore-scale particle migration was carried out using the finite element method (Juanes et al., 2002; Aarnes et al., 2006). The essence of finite element method is to divide a complex continuum into a finite number of grids, turn the infinite degree of freedom problem into a finite problem, and transform the solving of the (partial) differential equations into the algebraic equations. The governing equations of the fluid 
are shown in Eqs. (3) and (4), and the governing equation of the solid particles is shown in Eq. (5).

$$
\begin{gathered}
\rho \frac{\partial u}{\partial t}+\rho(u \cdot \nabla) u=\nabla \cdot[-p+K]+F \\
\rho \nabla \cdot u=0 \\
\frac{d\left(m_{p} v\right)}{d t}=F_{t}
\end{gathered}
$$

where $\rho$ is the density $\left(\mathrm{kg} / \mathrm{m}^{3}\right), u$ is the velocity $(\mathrm{m} / \mathrm{s}), p$ is the pressure $(\mathrm{Pa}), K$ is the viscous stress tensor $(\mathrm{Pa}), F$ is the volume force $\left(\mathrm{N} / \mathrm{m}^{3}\right), m_{p}$ is the particle mass $(\mathrm{kg}), v$ is the particle velocity $(\mathrm{m} / \mathrm{s}), F_{t}$ is the total force exerted on the particle $(\mathrm{N})$.

\section{Results and discussion}

\subsection{Experimental analysis of formation damage}

\subsubsection{Analysis of core-scale experimental data}

Under the condition that the confining pressure was always higher than the inlet pressure by $2 \mathrm{MPa}$, the experiments of two core samples were conducted with an inlet flow rate of $0.5 \mathrm{~mL} / \mathrm{min}$ until the outlet flow rate was equal to the inlet flow rate.

The experimental data of $1 \#$ core are shown in Table 4. The pressure differences at the final stable state in the three processes were $0.17,0.41$ and $0.30 \mathrm{MPa}$, respectively, among which the pressure difference after the reverse injection of reagent 1 was the largest. The permeabilities measured after the three processes were $7.52,4.89$ and $4.40 \mathrm{mD}$ respectively, which showed a decrease trend. The damage rates of the reverse injection and second formation water injection were $34.88 \%$ and $41.46 \%$ respectively. The increase of damage rate indicates that the injection of chemical reagent 1 caused some damages to the pore structure of the $1 \#$ core.

As shown in Fig. 3, the first formation water injection increased rapidly to $0.04 \mathrm{MPa}$, then slowly rose to $0.17 \mathrm{MPa}$, and then remained almost unchanged. The reserve injection curve of the reagent 1 reached the peak value of $0.46 \mathrm{MPa}$ with a rapid upward trend, and then slowly decreased to 0.41 $\mathrm{MPa}$, and then maintained a stable state. The inlet pressure of the second formation water injection curve quickly reached $0.30 \mathrm{MPa}$, and maintained a relatively stable trend until the end. Finally, the inlet pressure curve in the stable state was in order from high to low: reverse injection of reagent $1>$ second formation water injection $>$ first formation water injection.

Fig. 4 shows the change of inlet pressure of the $2 \#$ core. The inlet pressure in the experiment of first formation water injection increased quickly to $0.32 \mathrm{MPa}$, then slowly reached the peak value of $0.49 \mathrm{MPa}$, and finally remained at about $0.47 \mathrm{MPa}$ after a slight decline. The curve of reverse injection increased rapidly and intersected the curve of second injection

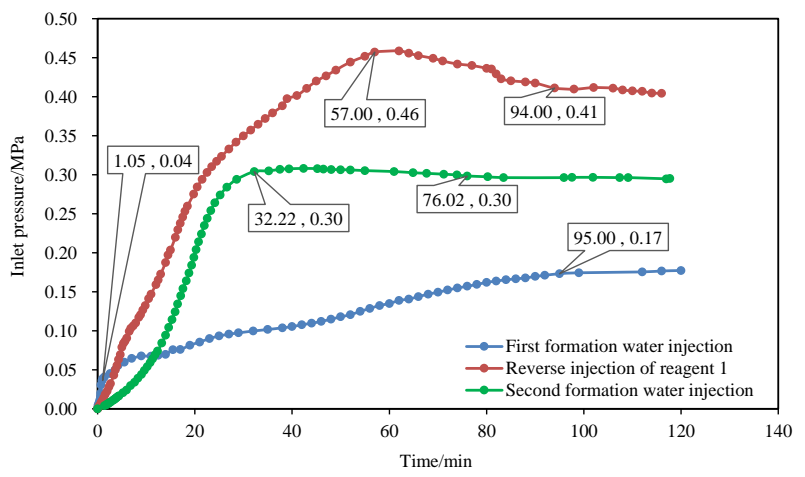

Fig. 3. Inlet pressure curve of the $1 \#$ core.

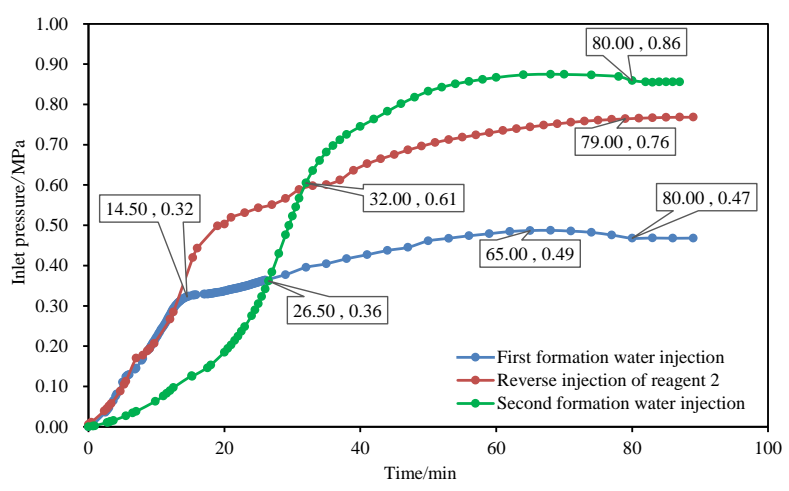

Fig. 4. Inlet pressure curve of the $2 \#$ core.

Table 4. Experimental data of $1 \#$ core.

\begin{tabular}{llll}
\hline & First formation water injection & Reverse injection of reagent 1 & Second formation water injection \\
\hline Pressure difference $(\mathrm{MPa})$ & 0.17 & 0.41 & 0.30 \\
Permeability $(\mathrm{mD})$ & 7.52 & 4.89 & 4.40 \\
Damage rate $(\%)$ & - & 34.88 & 41.46 \\
\hline
\end{tabular}

Table 5. Experimental data of 2\# core.

\begin{tabular}{llll}
\hline & First formation water injection & Reverse injection of reagent 2 & Second formation water injection \\
\hline Pressure difference $(\mathrm{MPa})$ & 0.47 & 0.76 & 0.86 \\
Permeability $(\mathrm{mD})$ & 2.62 & 2.00 & 1.43 \\
Damage rate $(\%)$ & - & 23.90 & 45.31 \\
\hline
\end{tabular}




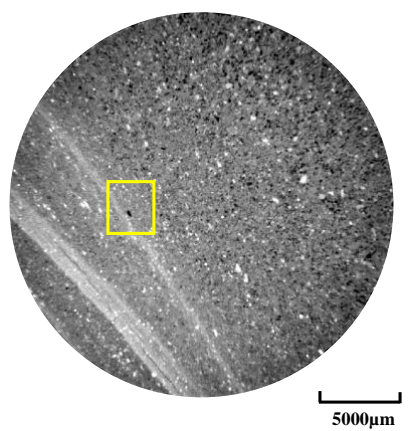

(a)

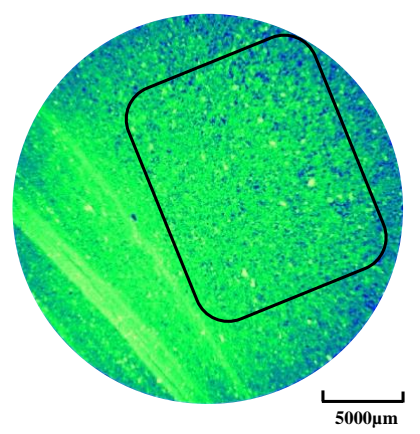

(d)

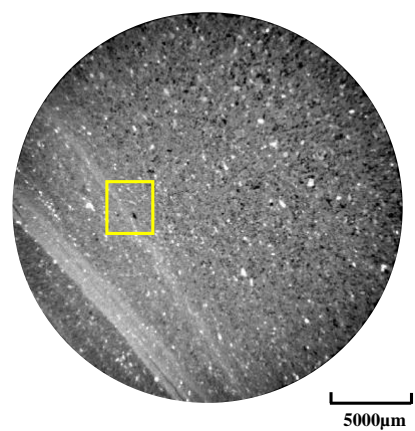

(b)

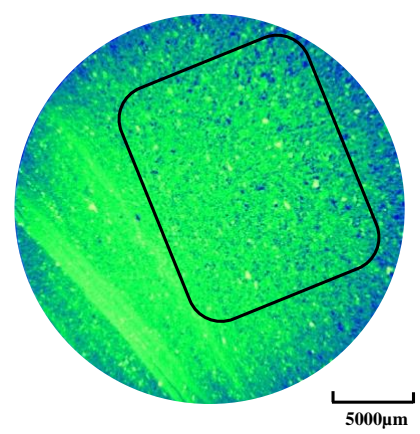

(e)

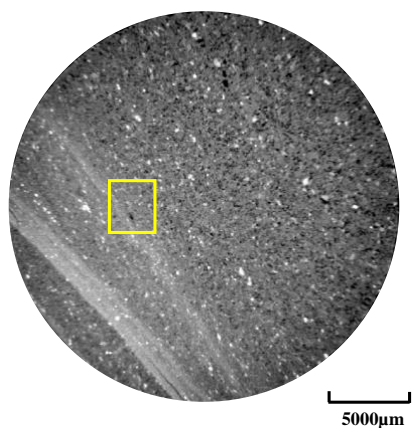

(c)

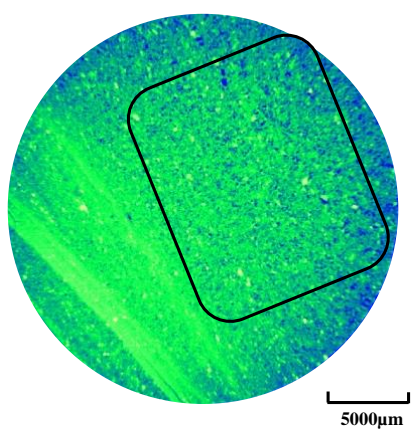

(f)

Fig. 5. Slices of $1 \#$ core ((a), (b) and (c) are first formation water injection state, reagent 1 state and second formation water injection state, respectively. (d), (e) and (f) are the rendering images corresponding to slices (a), (b) and (c): blue parts represent pores, green parts represent skeleton and matrix).

at $0.61 \mathrm{MPa}$ at first, and then increased slowly to reach the value of $0.76 \mathrm{MPa}$. The curve of the second formation water injection reached to $0.86 \mathrm{MPa}$ at the stable state. The experimental data of $2 \#$ core are shown in Table 5. The permeabilities measured after the three processes were 2.62 , 2.00 and $1.43 \mathrm{mD}$, respectively. From the reverse injection to the second formation water injection, the damage rate increased from $23.90 \%$ to $45.31 \%$.

\subsubsection{Particle migration}

\section{(1) Particle migration of $1 \#$ core}

Fig. 5 shows the grayscale slice images and rendered images corresponding to the three experiments. The pores in the yellow squares of slice (a), (b) and (c) were compared, among which the color of pores in (a) was the darkest and clearest, the pores in (b) had a slightly lighter color, and (c) had the faintest color. It indicates that during the three processes, the pore spaces were gradually blocked. By comparing the black box regions in (d), (e) and (f), we found that the proportion of blue parts in (f) was the largest, and (e) had the smallest proportion. This indicates that the (f) slice had the most pores and the particles inside the rock moved continuously during the experiment.

\section{(2) Particle migration of 2\# core}

Three grayscale slices of $2 \#$ core were compared in Fig. 6 . It could be seen from the yellow square that the proportion of black pores in (a) was the largest; (b) had the smallest pore proportion; the pores in (c) were generally fuzzy and lighter in color. The change in the number of pores could be clearly seen from the three rendered images (d), (e) and (f). The number of blue parts was the most in (f) and the least in (e).

\subsubsection{Microstructure of pores and throats}

\section{(1) Analysis of digital rock and pore network model}

The changes of the inner space of the core are shown in Figs. 7 and 8. Longitudinally, these images are under the conditions of first formation water injection, reverse chemical injection, and second formation water injection. By the comparison of the pore network model (c) (f) (i) in Figs. 7 and 8, it is found that both the $1 \#$ core and the $2 \#$ core have a sensitive region (the top of the $1 \#$ core and the left of the $2 \#$ core), which is called "sensitive region". Under the action of chemical reagents, the seepage channels in these sensitive areas expand firstly and then shrink. The reason is that in the process of reverse chemical reagents injection, seepage channels first appear at these sensitive regions due to the corrosion of chemical reagents. However, the subsequent second formation water injection destroyed some of the previously appeared seepage channels.

\section{(2) Analysis of pore throat parameters}

\section{(a) 1\# core}

To analyze the change of pore structure comprehensively and quantitatively, based on pore network models, we obtained the pore throat parameters of the core (Yang et al., 2015).

Fig. 9 shows the probability distributions of pore radius, throat radius, coordination number and tortuosity after the first formation water injection experiment, reverse injection of reagent 1 experiment and second formation water injection 


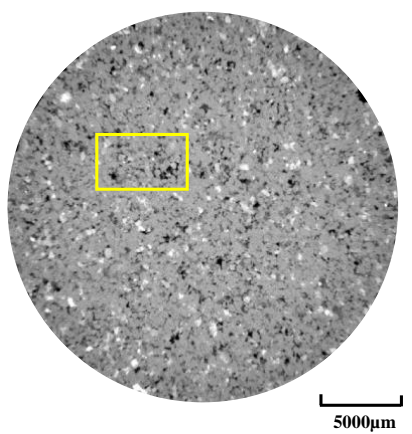

(a)

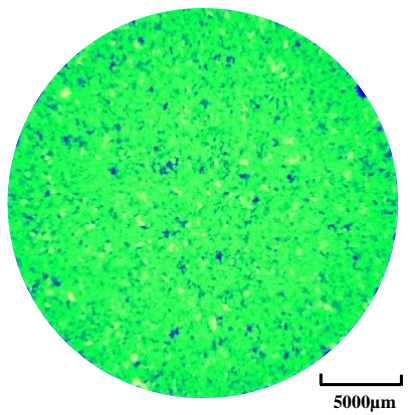

(d)

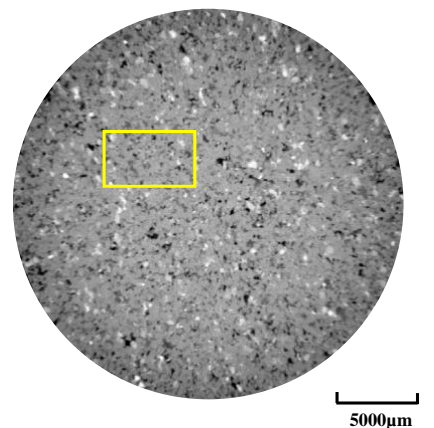

(b)

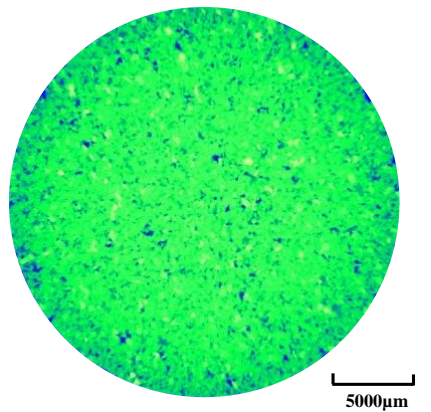

(e)

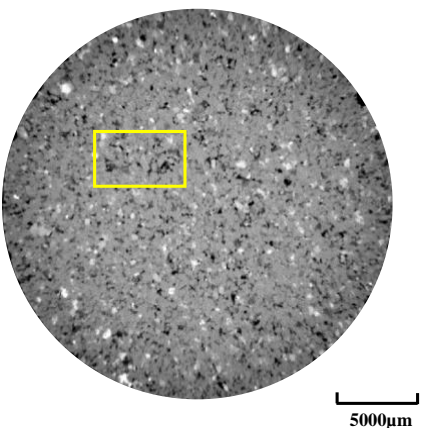

(c)

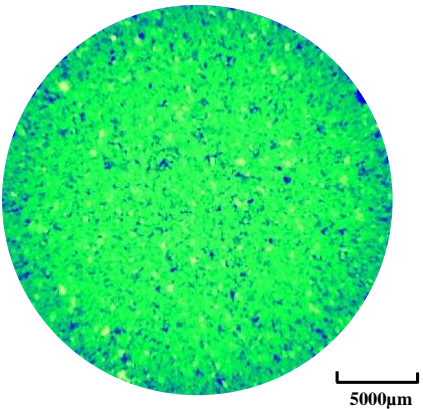

(f)

Fig. 6. Slices of $2 \#$ core ((a), (b) and (c) are first formation water injection state, reagent 2 state and second formation water injection state, respectively. (d), (e) and (f) are the rendering images corresponding to (a), (b) and (c): blue parts represent pores, green parts represent skeleton and matrix).

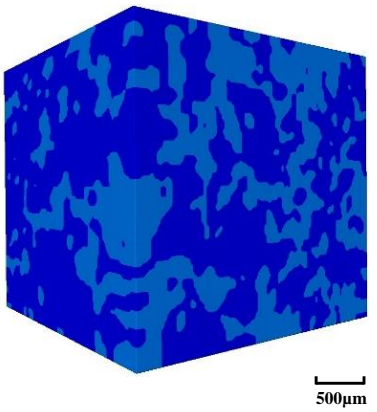

(a)

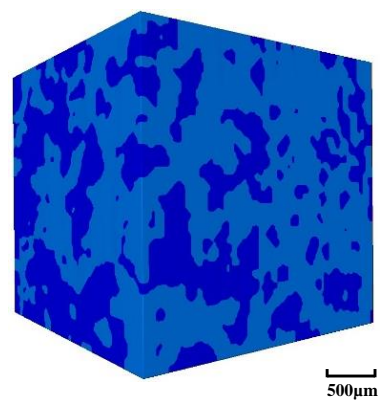

(d)

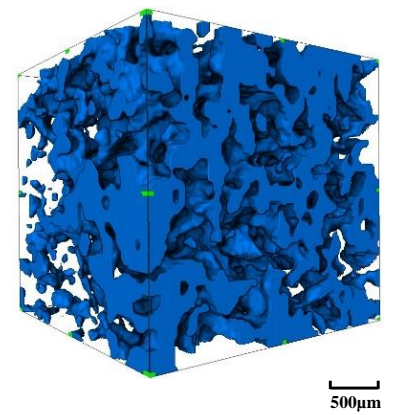

(b)

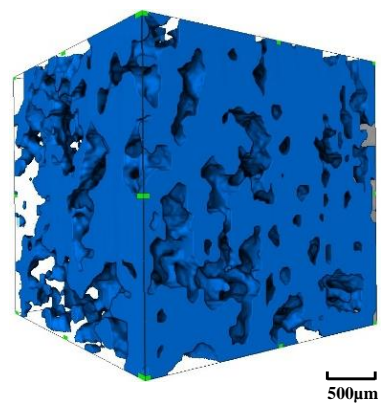

(e)

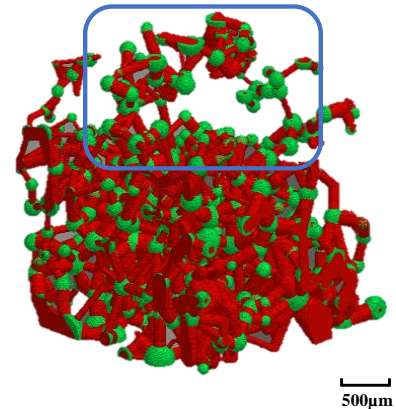

(c)

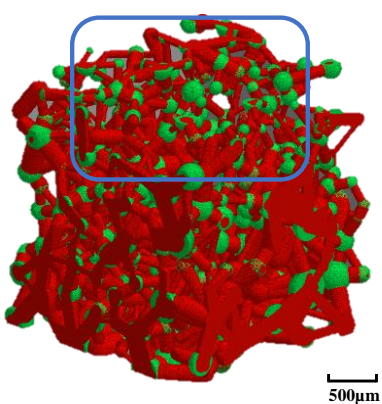

(f) 


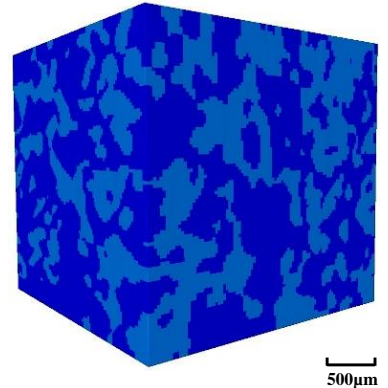

(g)

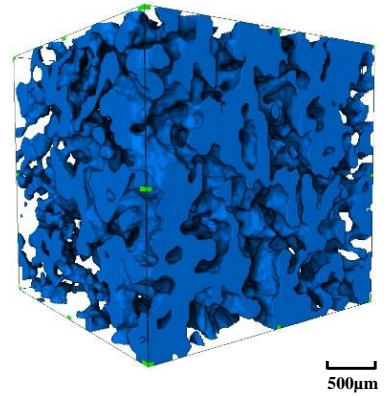

(h)

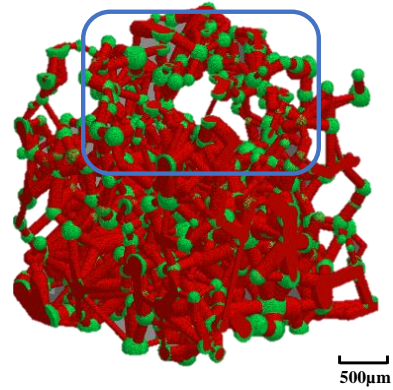

(i)

Fig. 7. Digital core and pore network model of 1\# sandstone ((a), (d) and (g) are digital cores during the first formation water injection, the reverse reagent 1 injection and the second formation water injection, respectively. (b), (e) and (h) are pore spaces during the three processes. (c), (f) and (i) are pore network models during the three processes).

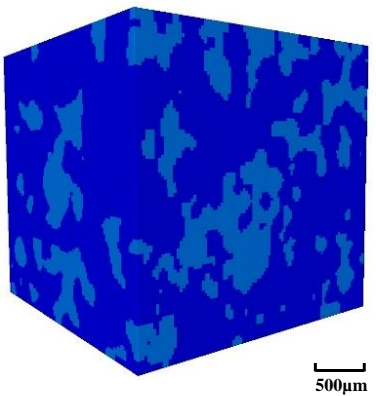

(a)

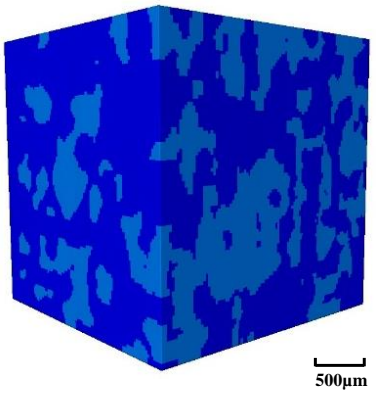

(d)

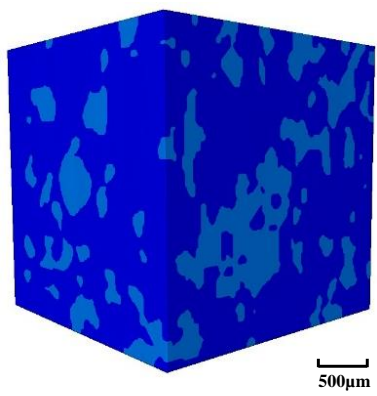

(g)

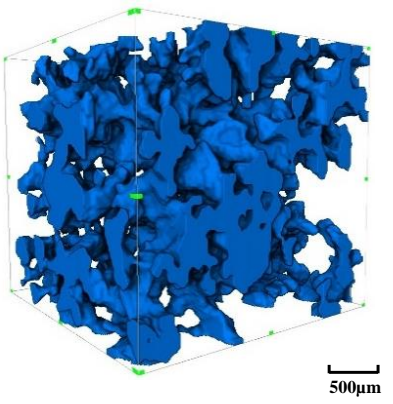

(b)

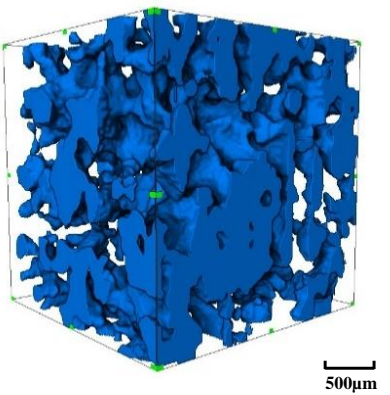

(e)

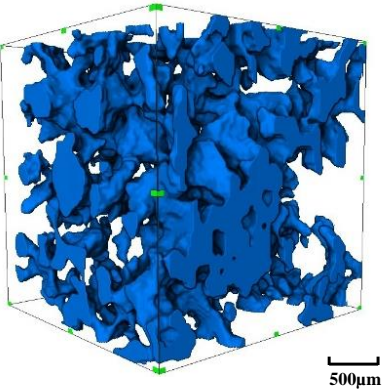

(h)

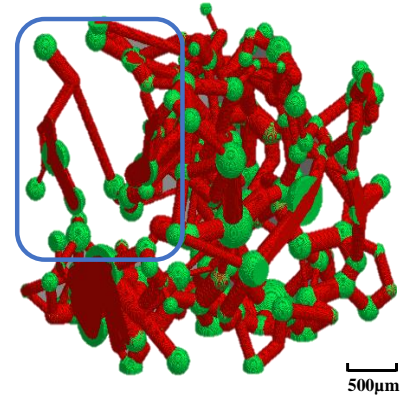

(c)

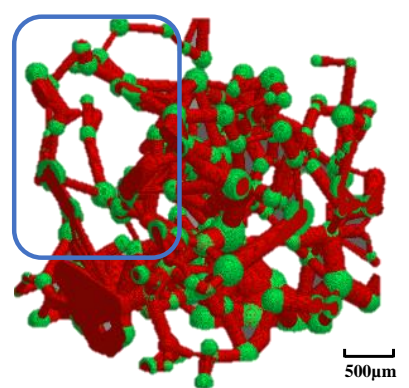

(f)

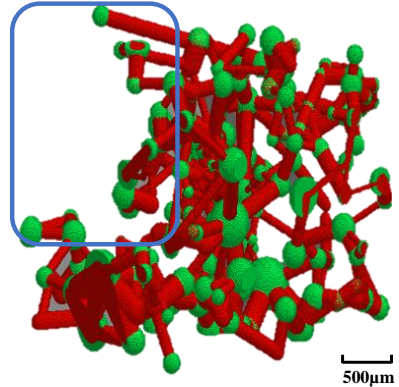

(i)

Fig. 8. Digital core and pore network model of 2\# sandstone ((a), (d) and (g) are digital cores during the first formation water injection, the reverse reagent 2 injection and the second formation water injection, respectively. (b), (e) and (h) are pore spaces during the three processes. (c), (f) and (i) are pore network models during the three processes). 


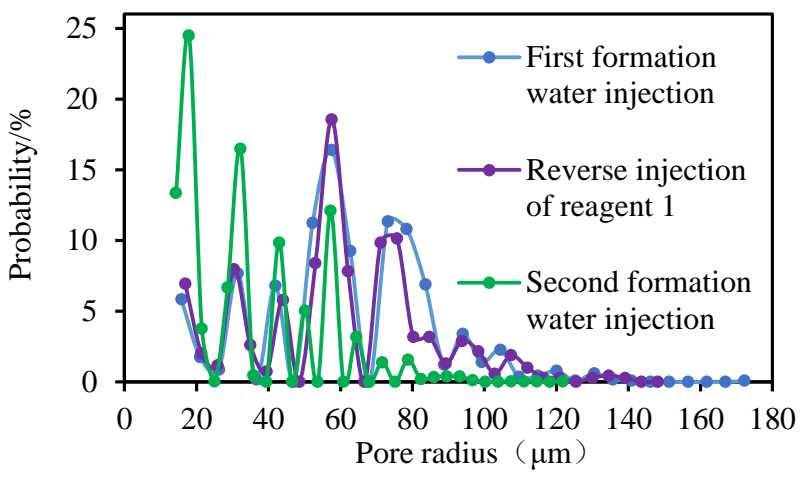

(a) Probability distribution of pore radius

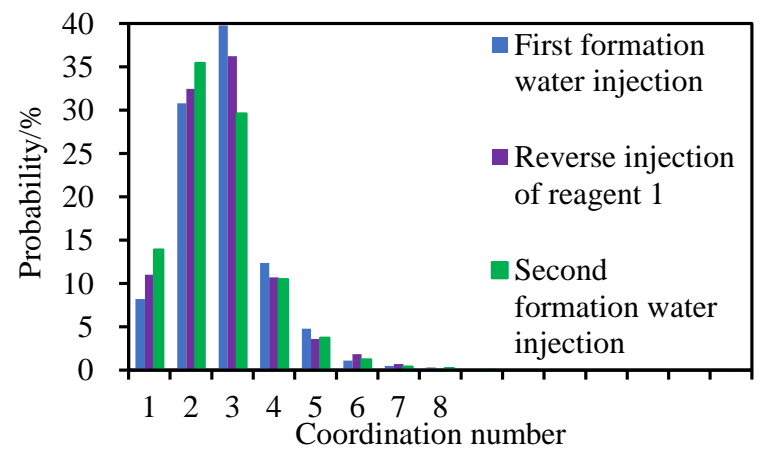

(c) Probability distribution of coordination number

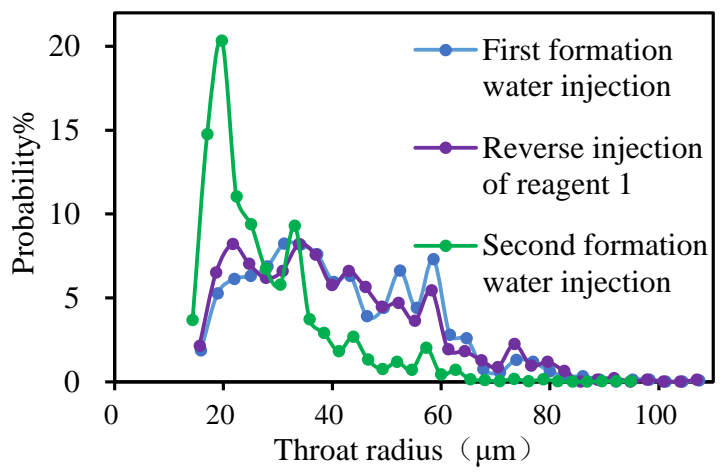

(b) Probability distribution of throat radius

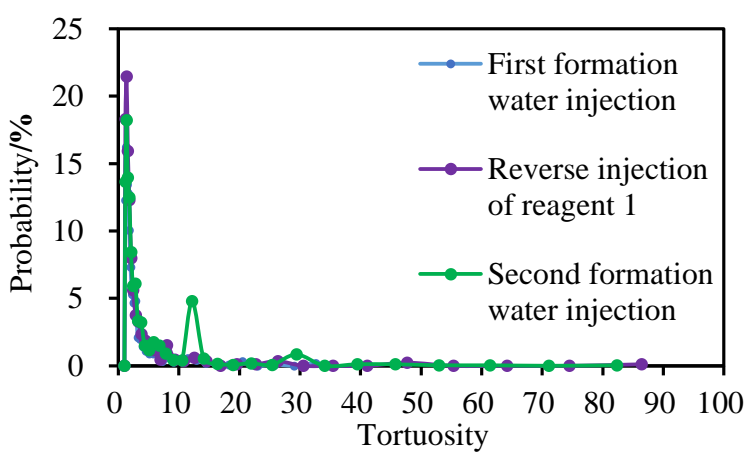

(d) Probability distribution of tortuosity

Fig. 9. Probability distribution diagram of pore structure parameters of $1 \#$ core ((a), (b), (c) and (d) are pore radius, throat radius, coordination number and tortuosity, respectively).

Table 6. Statistical table of pore structure parameters of $1 \#$ core.

\begin{tabular}{llll}
\hline Experimental process & Mean pore radiu $R_{p}(\mu \mathrm{m})$ & Mean throat radius $R_{t}(\mu \mathrm{m})$ & Mean coordination numbe $Z$ \\
\hline First formation water injection & 61.82 & 41.14 & 2.76 \\
Reverse injection of reagent 1 & 60.09 & 40.04 & 2.31 \\
Second formation water injection & 33.94 & 27.33 & 2.52 \\
\hline
\end{tabular}

experiment. As can be seen from Fig. 9(a), the pore radius of the three experimental processes is distributed between 10 and $170 \mu \mathrm{m}$, and mainly between 20 and $80 \mu \mathrm{m}$. Comparing the probability distribution of pore radius between the first formation water injection and reverse injection process, they have similar peak values and probabilities. However, in the second formation water injection process, compared with the first two processes, the probability of pore distribution peak appearing in the range of $20-40 \mu \mathrm{m}$ is significantly higher than the other two processes. Fig. 9(b) shows the comparison of probability distribution of throat radius of the three processes. The throat radius of the three processes are distributed between 15 and $120 \mu \mathrm{m}$, mainly between 20 and $60 \mu \mathrm{m}$. When the throat radius is between 20 and $60 \mu \mathrm{m}$, the probability distributions of the first formation water injection and the reverse injection process are similar, but the probability distribution of the second formation water injection process is significantly different from the other two processes. Coordination number refers to the number of throats connected to the pore. Fig. 9(c) shows the coordination number distribution probability of the three processes, and coordination number is mainly distributed between 2 and 4 . When the coordination number is the same, the probability distribution difference of the three processes is not more than $10 \%$. Tortuosity is defined as the ratio of the lengths of the preferential tortuous fluid pathways and the porous media. Fig. 9(d) shows that the tortuosity of the three processes is mainly distributed between 1 and 5, and the probability distribution of the reverse injection process is the largest.

Table 6 shows the average pore radius, average throat radius, average coordination number and average tortuosity of the three experimental processes of the 1\# core. As can be 


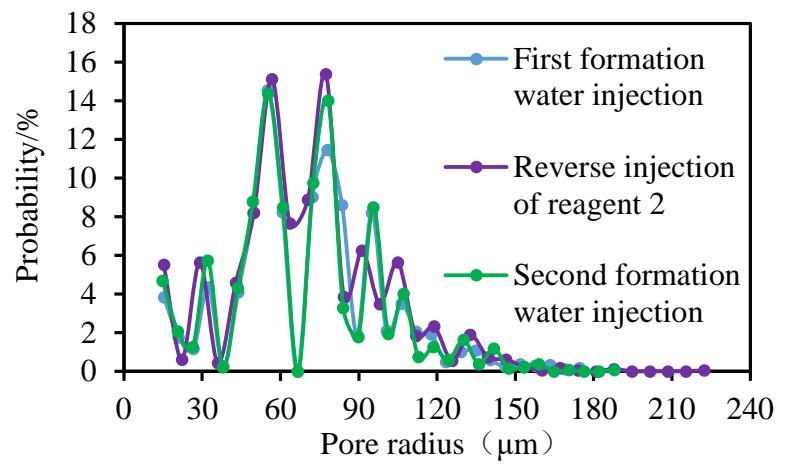

(a) Probability distribution of pore radius

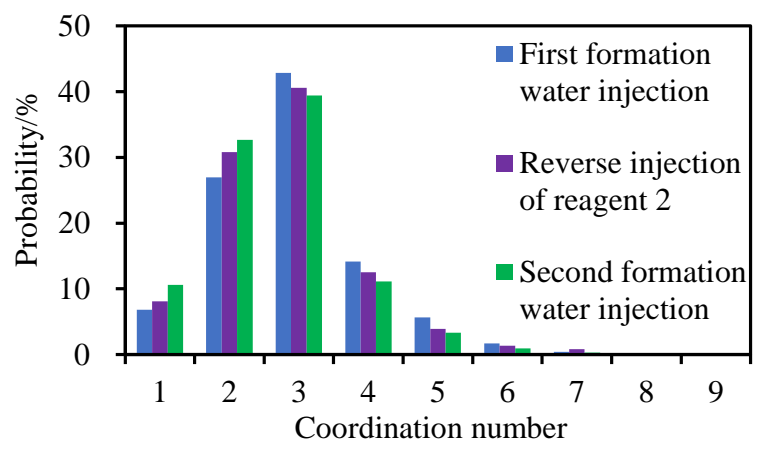

(c) Probability distribution of coordination number

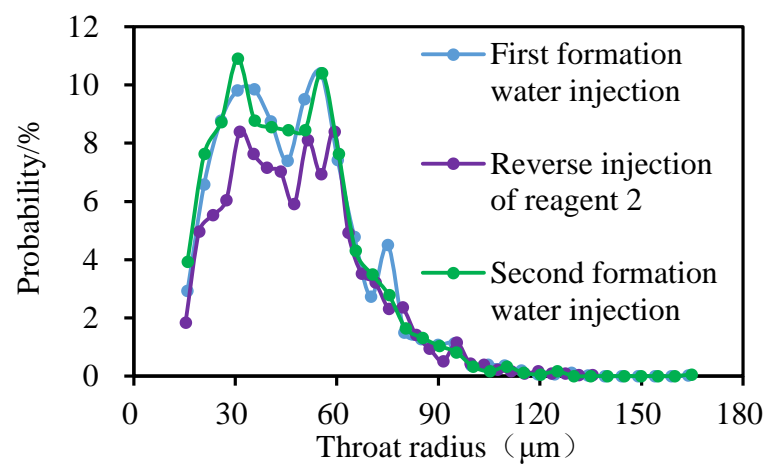

(b) Probability distribution of throat radius

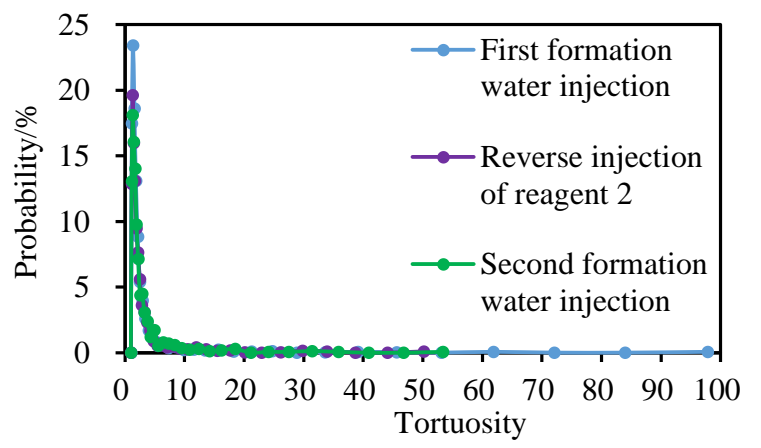

(d) Probability distribution of tortuosity

Fig. 10. Probability distribution diagram of pore structure parameters of $2 \#$ core ((a), (b), (c) and (d) are pore radius, throat radius, coordination number and tortuosity, respectively).

Table 7. Statistical table of pore structure parameters of $2 \#$ core.

\begin{tabular}{llll}
\hline Experimental process & Mean pore radiu $R_{p}(\mu \mathrm{m})$ & Mean throat radius $R_{t}(\mu \mathrm{m})$ & Mean coordination numbe $Z$ \\
\hline First formation water injection & 70.93 & 46.98 & 2.90 \\
Reverse injection of reagent 2 & 69.99 & 48.03 & 2.18 \\
Second formation water injection & 68.38 & 45.85 & 2.23 \\
\hline
\end{tabular}

seen from the table, the core pore parameters during the first formation water injection process are the best, with an average pore radius of $61.82 \mu \mathrm{m}$ and an average throat radius of $41.14 \mu \mathrm{m}$. In the second formation water injection process, the pore parameters were the worst, with average pore radius and average throat radius being 33.94 and $27.33 \mu \mathrm{m}$, respectively. From the top to the bottom, the average coordination number decreases and the average tortuosity increases.

\section{(b) $2 \#$ core}

The probability distributions of pore radius, throat radius, coordination number and tortuosity after the first formation water injection experiment, reverse injection of reagent 2 experiment and second formation water injection experiment were calculated, as shown in Fig. 10. As can be seen from Fig. 10(a), the probability distribution of pore radius of the three experimental processes is between 20 and $230 \mu \mathrm{m}$, which is mainly distributed between 20 and $120 \mu \mathrm{m}$. Pore size distribution and their corresponding probability of the three processes are relatively close. Fig. 10(b) shows a comparison of the probability distribution of throat radius of the three processes. The throat radius of the three processes are distributed between 15 and $170 \mu \mathrm{m}$, mainly between 20 and $80 \mu \mathrm{m}$. When the throat radius is 30 and $60 \mu \mathrm{m}$, the throat radius corresponding to the peak probability is similar, but the order of probability distribution is: Second formation water injection $>$ First formation water injection $>$ reverse injection of reagent 2. In addition, as shown in Figs. 10(c) and (d), the coordination number and tortuosity distribution of cores in the three processes are relatively close, among which the coordination number is mainly distributed between 2 and 4, and the tortuosity is mainly distributed between 1 and 6 .

The average pore radius, average throat radius, average coordination number and average tortuosity of the 2\# core during the three experimental processes are shown in Table 7. By longitudinal observation of the four parameters of the three experimental processes, it can be found that the average 


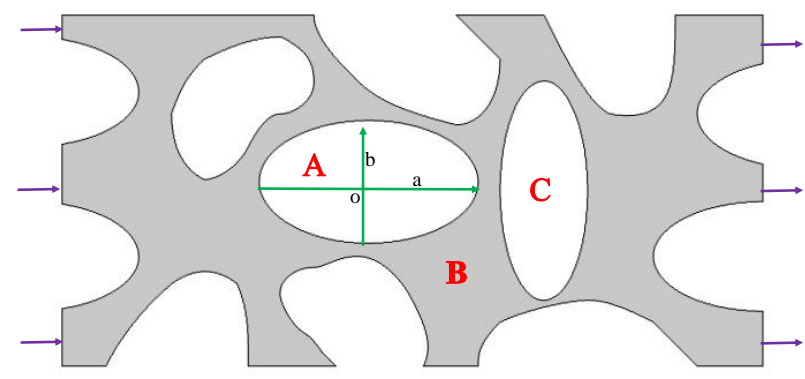

Fig. 11. Pore network model (Gray color is pore space and white part is matrix).

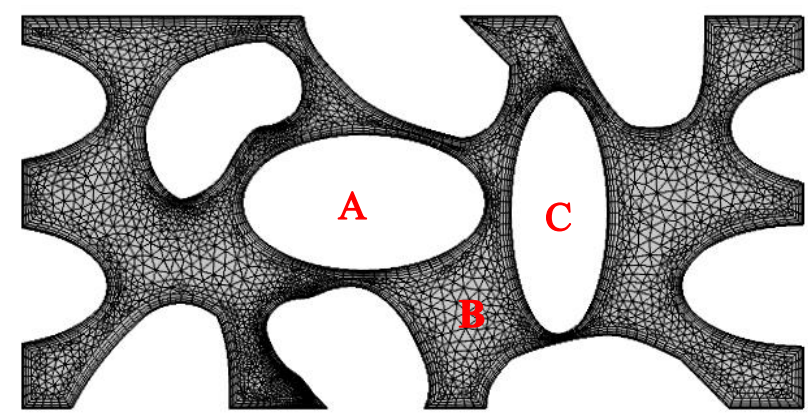

Fig. 12. Mesh generation model.

pore radius, the average throat radius and the average coordination number decrease and the average tortuosity increases after the reagent 2 reverse injection. It can be concluded that the injection of reagent 2 causes a certain degree of damage to the $2 \#$ core.

\subsection{Analysis of particle migration simulation}

In order to understand the rules of particle migration more clearly, we design a 2D microscopic seepage channel model according to the real core structure (An et al., 2016; Yang et al., 2020). As shown in Fig. 11, we build a 2D microscopic seepage channel model with a length of $64 \mu \mathrm{m}$ and a width of $32 \mu \mathrm{m}$. The left side is the inlet end and the right is the outlet. There are 9,835 grid cells in the model. And the time to run a single simulation is about 15 minutes. The grid subdivision image is shown in Fig. 12.

\subsubsection{Particle migration under different pressures}

In this study, the migration of solid particles was simulated under different inlet pressures $(1,000,3,000,6,000$ and 10,000 $\mathrm{Pa})$. The boundary condition was set as no slip, the number of solid particles was set as 20 , and the contact condition of solid particles and wall was set as rebound.

Fig. 13 shows the particles migration images under the four different pressures. The top legend is the velocity of the fluid, and the bottom legend is the velocity of the particle. According to the four images, we notice that the position and velocity of the particle migration are performed clearly under the different pressure states. Table 8 shows the statistical data of particle migration under different pressures. As can be seen from the table, with the rise of pressure, the number of solid particles passing through the outlet increases, and the export rate increases accordingly. When the formation is blocked due to the number of particle migration, appropriate measures can be taken to increase the formation pressure within the range of rock crushing pressure, so as to reduce the formation blockage.

\subsubsection{Particle migration under different degrees of expansion}

In this section, the inlet pressure was set as 3,000 $\mathrm{Pa}$, the boundary condition was set as no slip, the number of solid particles was set as 20 , and the contact condition of solid particles with the wall was set as rebound. We changed the degree of matrix deformation and observed the migration of solid particles under different degrees of matrix deformation.

$\mathrm{A}$ is the expansion area. The half axis $a$ remains unchanged, while the half axis $b$ changes as 5.6, 5.8, 6.0 and $6.2 \mu \mathrm{m}$, respectively; B and $\mathrm{C}$ are fixed areas with the same

Table 8. Statistical table of particle migration under different pressures.

\begin{tabular}{llll}
\hline Pressure $(\mathrm{Pa})$ & Total number of particles & Export number & Export rate $(\%)$ \\
\hline 1000 & 20 & 4 & 20 \\
3000 & 20 & 8 & 40 \\
6000 & 20 & 12 & 60 \\
10000 & 20 & 14 & 70 \\
\hline
\end{tabular}

Table 9. Statistical table of particle migration with different expansion degree.

\begin{tabular}{llll}
\hline Expansion axis $\mathrm{b}(\mu \mathrm{m})$ & Total number of particles & Export number & Export rate $(\%)$ \\
\hline 5.6 & 20 & 12 & 60 \\
5.8 & 20 & 8 & 40 \\
6.0 & 20 & 6 & 30 \\
6.2 & 20 & 5 & 25 \\
\hline
\end{tabular}




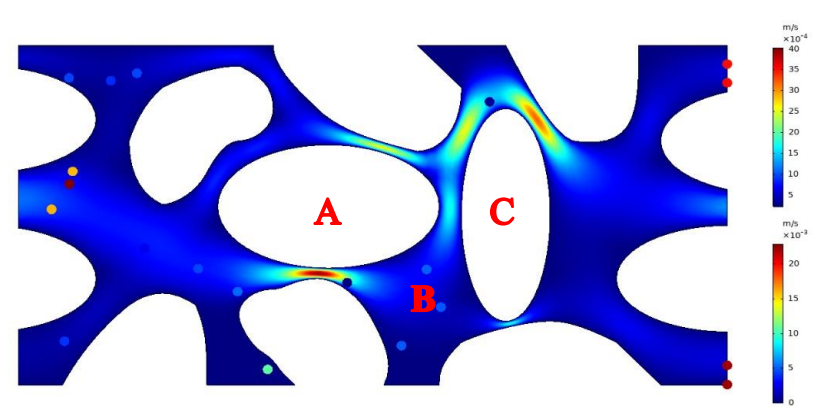

$\mathrm{P}=1000 \mathrm{~Pa}$

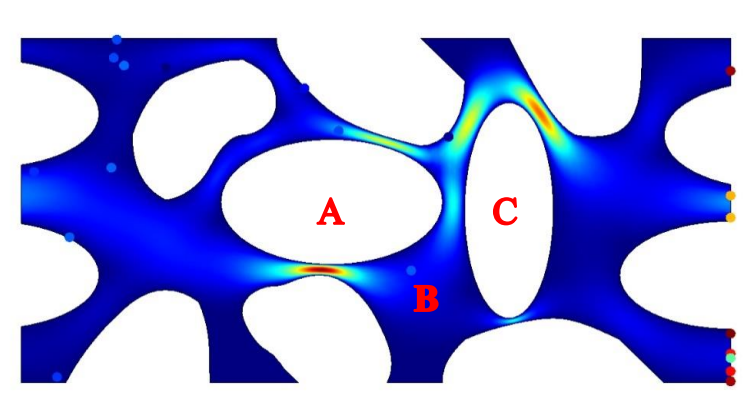

$\mathrm{P}=6000 \mathrm{~Pa}$

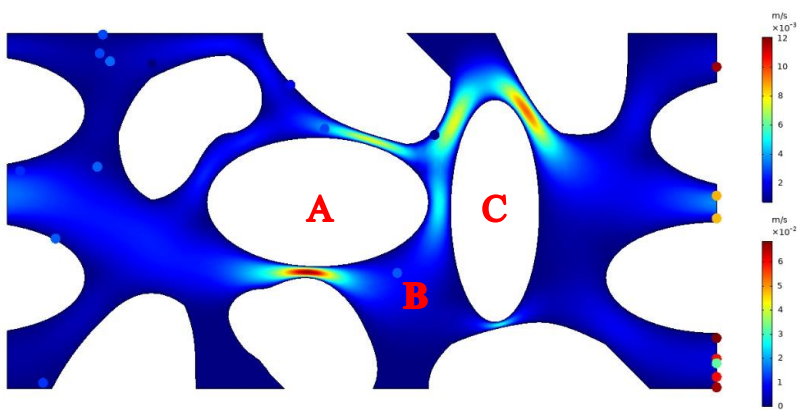

$\mathrm{P}=3000 \mathrm{~Pa}$

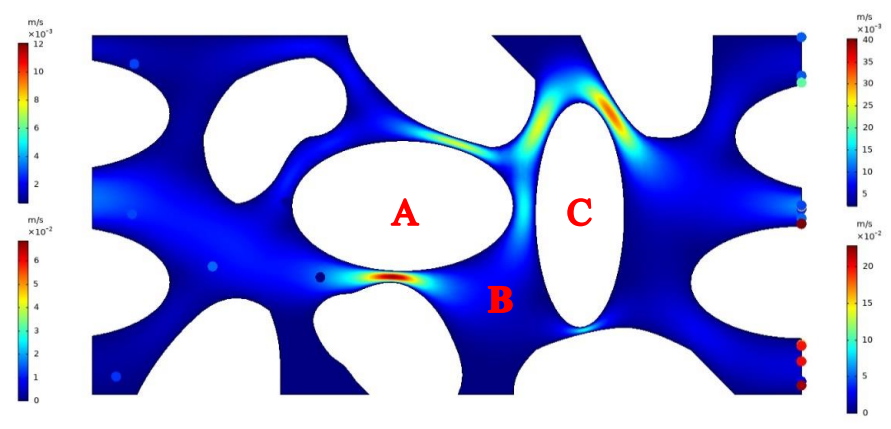

$\mathrm{P}=10000 \mathrm{~Pa}$

Fig. 13. Particle migration under different pressures.

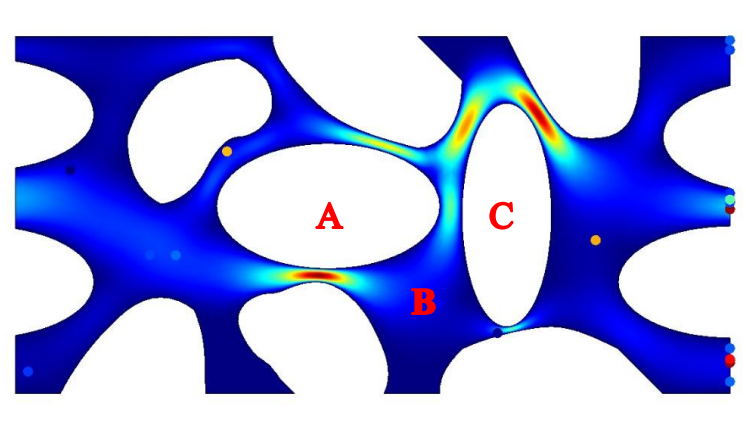

$\mathrm{b}=5.6 \mu \mathrm{m}$

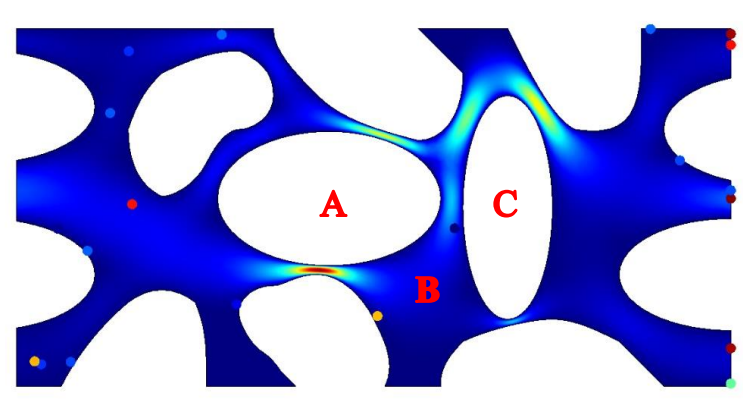

$\mathrm{b}=6.0 \mu \mathrm{m}$

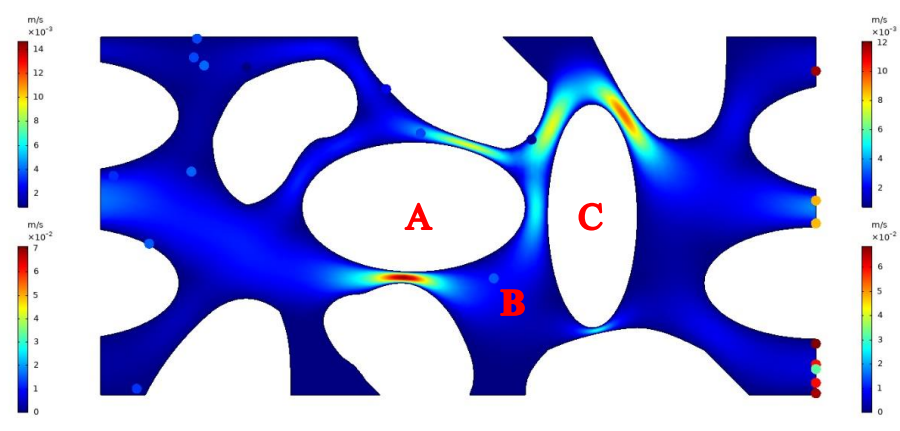

$\mathrm{b}=5.8 \mu \mathrm{m}$
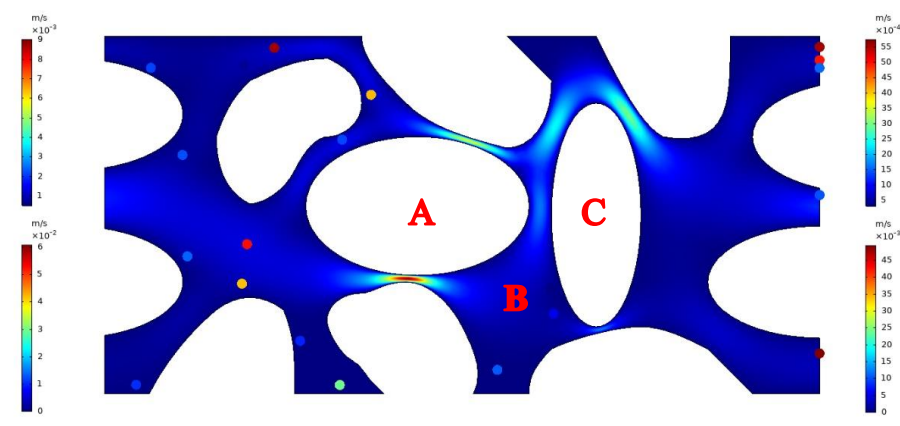

$\mathrm{b}=6.2 \mu \mathrm{m}$

Fig. 14. Velocity field distribution under different expansion axis b. 


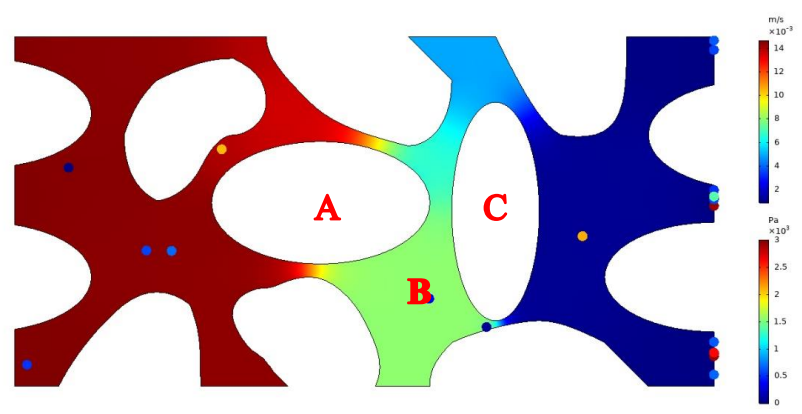

$\mathrm{b}=5.6 \mu \mathrm{m}$

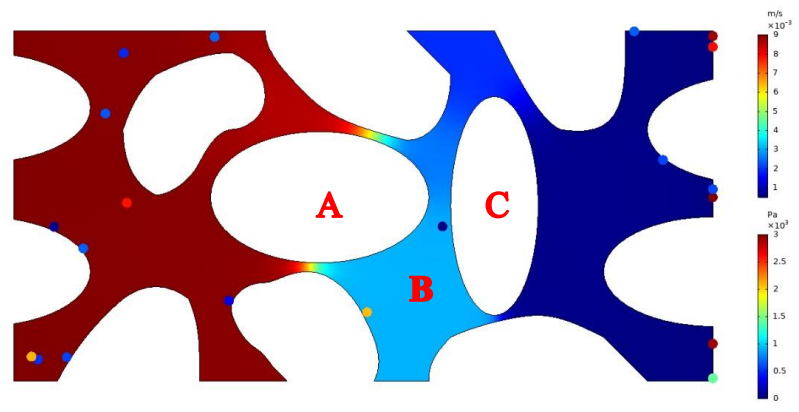

$\mathrm{b}=6.0 \mu \mathrm{m}$

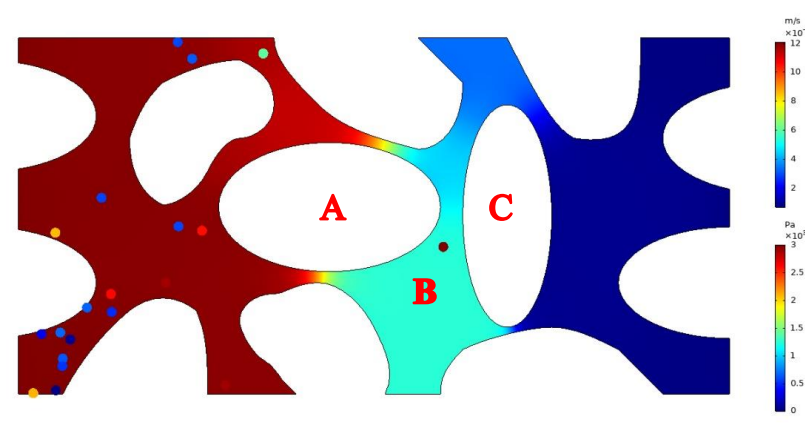

$\mathrm{b}=5.8 \mu \mathrm{m}$

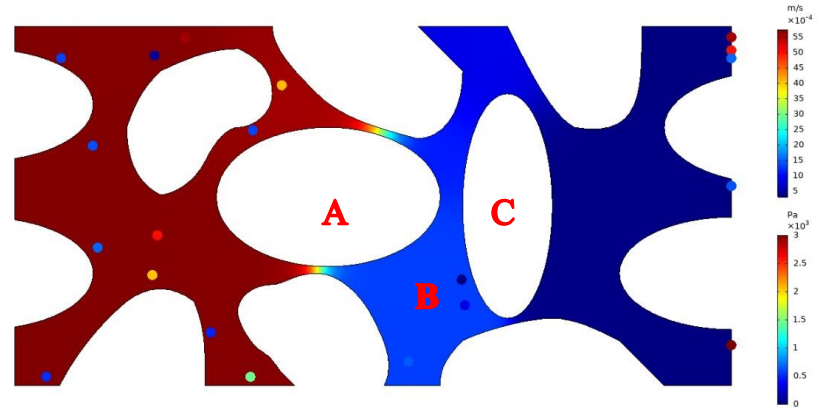

$\mathrm{b}=6.2 \mu \mathrm{m}$

Fig. 15. Pressure field distribution under different expansion axis b.

size (Fig. 11).

The particle migration data of the expansion half axis $b$ $=5.6 \mu \mathrm{m}, \mathrm{b}=5.8 \mu \mathrm{m}, \mathrm{b}=6.0 \mu \mathrm{m}$ and $\mathrm{b}=6.2 \mu \mathrm{m}$ were simulated respectively, as shown in Table 9.

As can be seen from the Table 9, with the increase of the expansion half axis $b$, the export rate of particles passing through the outlet gradually decreases. The reason is that with the increase of the expansion half axis, the seepage diameter around zone A decreases, which increases the difficulty of particles migration in the seepage channel.

Through simulation, the velocity field distribution under four different expansion axis b is obtained, as shown in Fig. 14. The top legend is the velocity of the fluid, and the bottom legend is the velocity of the particle. By comparing the above four images, we find that with the increase of expansion axis $\mathrm{b}$, the flow velocity of the fluid in seepage channel around zones $\mathrm{A}$ and $\mathrm{C}$ shows a decline, and there is also a decrease of flow velocity of solid particles in the fluid.

Fig. 15 shows the pressure distribution of the fluid under different expansion axis b. By comparing the four images, it is found that with the increase of the expansion axis $b$ in area $\mathrm{A}$, the seepage channel around area A decreases, which makes the color change of the left part of area B and C obviously: dark green - light green - light blue - dark blue. According to the legend, the pressure on the left of zone B and Zone C decreases with the rise of the expansion half axis $b$.

\section{Conclusions}

(1) To study the damages of chemical reagents to the target reservoir, we carried out the displacement experiments of chemical reagents. According to the experimental data, we found that the injection of chemical reagents increased the inlet pressure and led to the decrease of core permeabilities.

(2) To study microscopic formation damage of reservoir, CT scans were performed on the cores in the three processes of displacement experiment. Based on the CT slices, we compared the pore structure changes of sandstone at different displacement processes, and found the phenomenon of particle migration.

(3) In order to understand the mechanisms of particle migration more clearly, we designed a 2D microscopic seepage channel model according to the real core structure. We found that when the degree of matrix deformation, the particle migration was more difficult. Thus, it was more likely to cause the blockage of seepage channels.

\section{Acknowledgement}

We would like to express appreciation to the following financial support: the National Natural Science Foundation of China (51674280 and 51950410591), Shandong Provincial Natural Science Foundation (ZR2019JQ21), the Fundamental Research Funds for the Central Universities (20CX02113A), and Program for Changjiang Scholars and Innovative Research Team in University (IRT_16R69).

\section{Conflict of interest}

The authors declare no competing interest.

Open Access This article is distributed under the terms and conditions of the Creative Commons Attribution (CC BY-NC-ND) license, which permits unrestricted use, distribution, and reproduction in any medium, provided the original work is properly cited. 


\section{References}

Aarnes, J. E., Krogstad, S., Lie, K. A. A hierarchical multiscale method for two-phase flow based upon mixed finite elements and nonuniform coarse grids. Multiscale Modeling \& Simulation, 2006, 5(2): 337-363.

Ali, M., Arif, M., Sahito, M. F., et al. $\mathrm{CO}_{2}$-wettability of sandstones exposed to traces of organic acids: Implications for $\mathrm{CO}_{2}$ geo-storage. International Journal of Greenhouse Gas Control, 2019, 83: 61-68.

Al-Yaseri, A. Z., Lebedev, M., Vogt, S. J., et al. Pore-scale analysis of formation damage in Bentheimer sandstone with in-situ NMR and micro-computed tomography experiments. Journal of Petroleum Science and Engineering, 2015, 129: 48-57.

An, S., Yao, J., Yang, Y., et al. Influence of pore structure parameters on flow characteristics based on a digital rock and the pore network model. Journal of Natural Gas Science and Engineering, 2016, 31(4): 156-163.

Bagci, S., Kok, M. V., Turksoy, U. Determination of formation damage in limestone reservoirs and its effect on production. Journal of Petroleum Science and Engineering, 2000, 28(1-2): 1-12.

Borazjani, S., Behr, A., Genolet, L., et al. Effects of fines migration on low-salinity waterflooding: Analytical modelling. Transport in Porous Media, 2017, 116(1): 213-249.

Guo, X., Shen, Y., He, S. Quantitative pore characterization and the relationship between pore distributions and organic matter in shale based on nano-CT image analysis: A case study for a lacustrine shale reservoir in the triassic chang 7 member, ordos basin, china. Journal of Natural Gas Science and Engineering, 2015, 27: 1630-1640.

Hussain, F., Zeinijahromi, A., Bedrikovetsky, R., et al. An experimental study of improved oil recovery through fines-assisted waterflooding. Journal of Petroleum Science and Engineering, 2013, 109: 187-197.

Izgec, O., Demiral, B., Bertin, $\mathrm{H}$., et al. $\mathrm{CO}_{2}$ injection into saline carbonate aquifer formations $\mathrm{I}$ : Laboratory investigation. Transport in Porous Media, 2008, 72(1): $1-24$.

Juanes, R., Samper, J., Molinero, J. A general and efficient formulation of fractures and boundary conditions in the finite element method. International Journal for Numerical Methods in Engineering, 2002, 54(12): 17511774.

Klise, K. A., Moriarty, D., Yoon, H., et al. Automated contact angle estimation for three-dimensional X-ray microtomography data. Advances in Water Resources, 2016, 95: 152-160.

Lemon, P., Zeinijahromi, A., Bedrikovetsky, P., et al. Effects of injected-water salinity on waterflood sweep efficiency through induced fines migration. Journal of Canadian Petroleum Technology, 2011, 50(9): 82-94.

Li, G., Tang, H., Xu, C., et al. Research on the formation damage to Penglaizhen Formation shallow gas reservoirs of Jurassic in west Sichuan Basin. Natural Gas Industry, 2003, 23(6): 79-81. (in Chinese)
Li, X., Zhang, G., Ge, J., et al. Potential formation damage and mitigation methods using seawater-mixed acid to stimulate sandstone reservoirs. Journal of Natural Gas Science and Engineering, 2016, 35: 11-20.

Liu, Z., Yang, Y., Yao, J., et al. Pore-scale remaining oil distribution under different pore volume water injection based on CT technology. Advances in Geo-Energy Research, 2017, 1(3): 171-181.

Luo, B., Guo, J., Fu, W., et al. Experimental investigation of shear slippage behavior in naturally fractured carbonate reservoirs using X-ray CT. International Journal of Rock Mechanics and Mining Sciences, 2019, 122: 104066.

Luquot, L., Roetting, T. S., Carrera, J. Characterization of flow parameters and evidence of pore clogging during limestone dissolution experiments. Water Resources Research, 2014, 50(8): 6305-6321.

Ma, K., Jiang, H., Li, J., et al. Experimental study on the micro alkali sensitivity damage mechanism in low-permeability reservoirs using QEMSCAN. Journal of Natural Gas Science and Engineering, 2016, 36: 1004-1017.

Ma, S., Zheng, J., Tang, D., et al. Application of X-ray computed tomography technology in gas hydrate. Energy Technology, 2019, 7(6): 1800699.

Moghadasi, J., Müller-Steinhagen, H., Jamialahmadi, M., et al. Model study on the kinetics of oil field formation damage due to salt precipitation from injection. Journal of Petroleum Science and Engineering, 2004, 43(3-4): 201-217.

Oliveira, M. A., Vaz, A. S. L., Siqueira, F. D., et al. Slow migration of mobilised fines during flow in reservoir rocks: Laboratory study. Journal of Petroleum Science and Engineering, 2014, 122: 534-541.

Wang, C., Yao, J., Yang, Y., et al. Percolation properties analysis of carbonate digital core based on lattice boltzmann method. Journal of China University of Petroleum (Edition of Natrual Sciences), 2012, 36(6): 94-98. (in Chinese)

Wang, H., Pang, Z., Liu, D., et al. Formation damage mechanism and controlling measures for heavy oil reservoir of steam injection. Acta Petrolei Sinica, 2009, 30(4): 555-559. (in Chinese)

Wang, J., Huang, Y., Zhou, F., et al. Study on reservoir damage during acidizing for high-temperature and ultra-deep tight sandstone. Journal of Petroleum Science and Engineering, 2020, 191: 107231.

Wang, X., Yin, H., Zhao, X., et al. Microscopic remaining oil distribution and quantitative analysis of polymer flooding based on CT scanning. Advances in Geo-Energy Research, 2019, 3(4): 448-456.

$\mathrm{Xu}, \mathrm{C}$., Kang, Y., You, Z., et al. Review on formation damage mechanisms and processes in shale gas reservoir: Known and to be known. Journal of Natural Gas Science and Engineering, 2016, 36: 1208-1219.

Yang, Y., Li, Y., Yao, J., et al. Formation damage evaluation of a sandstone reservoir via pore-scale X-ray computed tomography analysis. Journal of Petroleum Science and Engineering, 2019, 183: 106356. 
Yang, Y., Wang, K., Lv, Q., et al. Flow simulation considering adsorption boundary layer based on digital rock and finite element method. Petroleum Science, 2020, doi: 10.1007/s12182-020-00476-4.

Yang, Y., Yao, J., Wang, C., et al. New pore space characterization method of shale matrix formation by considering organic and inorganic pores. Journal of Natural Gas Science and Engineering, 2015, 27(Part2): 496-503.
Zhang, X., Lu, Y., Tang, J., et al. Experimental study on fracture initiation and propagation in shale using supercritical carbon dioxide fracturing. Fuel, 2017, 190: 370-378.

Zhao, Y., Zhao, J., Shi, D., et al. Micro-CT analysis of structural characteristics of natural gas hydrate in porous media during decomposition. Journal of Natural Gas Science and Engineering, 2016, 31: 139-148. 